\title{
A JURISPRUDENTIAL AND SOCIO-CULTURAL RECONSIDERATION OF THE RAPE-PHENONMENON
}

\author{
Edor J. Edor \\ Department of Philosophy, University of Calabar, Cross River State, Nigeria. \\ edorjb2k@gmail.com
}

\begin{abstract}
For sundry reasons, every human community is replete with aberrations of varying magnitude. Some aberrations become so through the criminalisation process by society, some other human acts are considered ontologically uncongenial to human nature. Driving on the left lane of the road in Nigeria, for example, is a traffic offence. It is so because Nigerian road traffic experts consider it convenient to keep right while driving, thereby criminalising driving on the left lane of the road. The aberration of driving on the left lane of the road cannot be said to be adorned with ontological colouration. The phenomenon of rape is considered an ontological aberration in this article and repugnant to human nature. Both the victim and the perpetrator of rape are exposed to social and psychological repercussions. Unfortunately, some of the repercussions on the victim of rape are unnecessary, as they are cosmetically imposed by society, and there is no necessary connection between the aberration and the social consequences. Some of the social and psychological consequences of the phenomenon of rape are considered in this work, and it is argued herein that the social consequences imposed on the victim of rape are unnecessary, and that they unnecessarily compound the traumas that the rape-victim suffers. It is, therefore, suggested herein that some cultural perceptions among most Nigerian tribes should be reviewed to ameliorate the repercussions of rape in the rape-victim.
\end{abstract}

Keywords: Audience, Drama, Nigeria, Reactions, Seismology, Series, Television.

\section{INTRODUCTION}

The prevalence of rape cases and their effects on the victim have been a major global concern. Unlike other crimes that are reported willingly to relevant authorities for prosecution, rape victims find it hard to report their cases for fear of stigmatisation in Nigeria. This is deeply influenced by the social attitude of the public to rape-victims which has continued to keep the victims quiet while the crime is on the increase. According to the Nigerian Observer, the National Human Rights Commission said that there were 2,656 domestic violence cases, including rape in 2012 alone (Nigerian observer). The assumption is that there would have been fewer cases of rape if all victims had the confidence to report their cases. One major reason why most rape-victims shy away from report rape cases is the factor of social stigmatisation by most Nigerian tribes. This fear of socio-cultural stigmatisation has kept many victims traumatised psychologically. Naturally, the phenomenon of psychological trauma often snow-balls into other social vices such as indulging in drug abuse, depression, etc. Some rape-victims end up committing suicide as a result of irretrievable depression.

Rape is an ontological aberration, as it violates the soul and dignity of both the rapevictim and the rape-perpetrator (Merab 2015; Yta 2015: Opasina 2016). Because of the perfidy associated with rape, most Nigerian tribes complicate the psychological trauma suffered by the rape-victim by casting social aspersions on her. Consequently, the rape-victim suffers the cumulative pains of the desecration of her soul and dignity and the artificially created social disdain. 


\section{UNDERSTANDING THE RAPE PHENOMENON}

Rape is a social phenomenon that has multifaceted ramifications: religious, sociological, moral, jurisprudential, legal, spiritual, etc. Consequently, the social phenomenon is viewed from variegated perspectives. Because of the different perspectives from which rape could be viewed, it is often subject to unnecessary controversies. In this work, rape is being looked at from the legal/jurisprudential perspective, before considering and analysing the socio-cultural and psychological implications it has on the rape-victim, the perpetrator, and the society at large. Black's Law Dictionary defines rape as follows:

At common law, unlawful sexual intercourse is committed by a man with a woman, not his wife through force and against her will. The common-law crime of rape required at least a slight penetration of the penis into the vagina. Also at common-law, a husband could not be convicted of raping his wife (Garner \& Black 2007: 1267).

In Nigeria, section 357 of the Criminal Code Act, Cap. C38, Laws of the Federation of Nigeria 2003 defines the crime of rape as:

Any person who has unlawful carnal knowledge of a woman or girl, without her consent, or with her consent if the consent is obtained by force or by means of threats or intimidation of any kind, or by fear of harm, or by means of false and fraudulent representation as to the nature of the act, or in the case of a married woman, by personating her husband, is guilty of an offence which is called rape.

Because the Nigerian legal system is of common-law origin, the striking connection of the common-law definition of rape and the Nigerian definition of rape as provided in section 357 of the Criminal Code Act is apparent. This definition of rape by section 357 of the Criminal Code Act has been expounded on by Nigerian courts. In the case of Idris Rabiu V. The State (2005) 1 NCC 578 at 590:

Rape is the unlawful carnal knowledge of a woman by a man forcibly and against her will. Or, put more tersely, it is the act of sexual intercourse committed by a man with a woman, not his wife and without her consent, committed when the woman's resistance is overcome by force or fear, or under other prohibitive conditions. It is a serious offence and attracts severe penalties under the various Criminal Codes operating in Nigeria.

While the Criminal Code Act is applicable in the southern states of Nigeria, in the northern states of Nigeria, the statute regulating criminal jurisprudence is known as the Penal Code Act. Section 282(1) of the Penal Code Act, Cap. 89, Laws of the Northern of Nigeria, 1963 provides that "a man is said to commit rape who, save where he had sexual intercourse with his wife, has sexual intercourse in any of the following circumstances: (a) against her will; (b) without her consent; (c) with her consent where has consent has been obtained by putting her in fear of death or of hurt; (d) with her consent, when the man knows that he is not her husband and that her consent is given because she believes that he is another man to whom she is or believes herself to be lawfully married; (e) with or without her consent when she is under fourteen years of age or of unsound mind". Another prohibitive condition under which sexual intercourse would occur and it amounts to rape against the man is sex when the woman or girl is under intoxication. Intoxication-induced consent for sexual intercourse is uninformed consent, as it is "consent" extracted under some form of duress.

Some of the prominent features of the definitions of rape, from the common-law understanding to the statutory and judicial definitions of rape in Nigeria, appear to be that a 
man cannot rape his wife, a woman cannot rape a man, and a man cannot rape a man. Drawing further implications from the definitions of rape presented above, it is the position of the law in Nigeria that a woman or girl cannot be convicted of rape, because she cannot rape a man or boy, and she cannot rape a fellow woman or girl. Crimen raptus is therefore gender discriminatory, at least, going by the extant laws in Nigeria. What could have engendered this jurisprudential disposition of the law of rape? In the first place, one of the vital elements that must be considered to ground a conviction on rape is penetration. The penetration of the vagina by the penis is an indispensable/essential element/ingredient of the crime rape (Ohayi \& Ezugwu 2019).

A woman or girl does not possess a penis, and would therefore be seen to lack the requisite instrument to commit rape. Should the language of the provision of the various definitions of rape be interpreted to mean penetration of the vagina by the penis as caused by anybody, the psychological factor which is a necessary associate in the exercise of sexual intercourse rears up. Though sex is a physiological exercise, the physiologicality of the exercise is not mutually exclusive of the psychologicality of the sex phenomenon (Smith 2016). It is the psychologicality in the exercise of sex that triggers the erection of the phallus and the wetness of the vulva. In this case then, a fluffy penis cannot be caused to penetrate the vagina, no matter how wet the vagina may be. A man who was to be "raped" is a man who has no intention for sexual intercourse, therefore, lacking in the psychologicality of the act. This means that the man will not have an erection. On the other hand, a woman or girl needs not necessarily be psychologically disposed of for the vulva to be penetrated. This is due to the hollow shape of the vagina. Though the physiologicality and the psychologicality are a composite sine qua non for a proper act of sexual intercourse, in the case of rape, the psychologicality is always absent, therefore leaving the penis fluffy (then incapable is being caused to have penetration), and leaving the vagina dry (yet penetration is possible because of the hollow shape of the vagina). In fact, the extent of penetration required to ground a conviction of rape is penetration no matter how slight. This then does not need a (very) wet vagina.

Another feature of the definition of rape aforementioned is the fact that a man cannot rape his wife. The overriding ingredient in the crimen raptus is consent, its availability, or non-availability. It appears to me, then, that by the very fact that a legitimate and proper marriage is subsisting, it becomes difficult to divest it of sexual consent. All forms of marriage come with marital obligations for both the wife and the husband, be it customary, Christian, or statutory marriage. Illuminating on this, Victor Nyoroh (2004: 132-133) writes:

Consortium means the conjugal fellowship of husband and wife and the right to each other's company, cooperation, affection and mutual assistance within one roof. It comprises not only material necessities like food, clothing and welfare, etc., but also companionship and exclusive sexual relationship coterminous with monogamous marriage. The consortium attaches to each partner certain rights and obligations towards each other, as the husband maintains the wife and the wife manages the household. It implies certainly cohabitation, i.e. living with the person, sharing the same bed, shelter and table together.

The fact that sexual intercourse is a marital obligation for the parties in marriage is further captured by another author thus:

The list of the benefits of marriage constituting consortium is not definite, it depends on the fact and circumstances of each case. This is why it is incapable of any precise 
legal definition. Nevertheless, some aspects of the consortium have been known to be common to almost all marriages and they include cohabitation, sexual intercourse, mutual protection, provision and use of name (Eja, 2003: 91).

Since a woman cannot rape a man, discussions of the foreclosure of rape in matrimony are directly restricted to a husband being incapable of raping his wife. One of the obligations a wife owes her husband in any marriage is the obligation of conjugality. The husband, then, has a corresponding right to sexual intercourse with his wife, which right arises from the obligation/duty of conjugality that the wife owes her husband.

That a husband is inured with the right to sexual intercourse from his wife, which right imposes a corresponding obligation/duty of conjugality on the wife, has never been in contention. The real jurisprudential concern here is to decipher whether this right of sex from a wife which the husband enjoys is unfettered and absolute. In the Nigerian criminal jurisprudence, gleaning from the statutory and judicial definitions of rape, it appears very strongly that it is the case that a husband cannot rape his wife (Felix et al., 2019). The prominence of the phrase "except his wife" in the various definitions of rape is indicative of the fact that a husband may not be constituted to be able to rape his wife, legally speaking. For convenience, we shall be reproducing two definitions of rape hitherto mentioned herein. Section 282(1) of the Penal Code Act, Cap. 89, Laws of the Northern of Nigeria, 1963 provides that:

a man is said to commit rape who, save where he had sexual intercourse with his wife, has sexual intercourse in any of the following circumstances: (a) against her will; (b) without her consent; (c) with her consent where has consent has been obtained by putting her in fear of death or of hurt; (d) with her consent, when the man knows that he is not her husband and that her consent is given because she believes that he is another man to whom she is or believes herself to be lawfully married; (e) with or without her consent, when she is under fourteen years of age or of unsound mind (emphasis mine).

In a similar vein, the Black's Law Dictionary also makes an exception in the case of rape for a husband who had sexual intercourse with a woman who is his wife. It defines rape as follows:

At common law, unlawful sexual intercourse is committed by a man with a woman, not his wife through force and against her will. The common-law crime of rape required at least a slight penetration of the penis into the vagina. Also at common-law, a husband could not be convicted of raping his wife (emphasis mine).

It could not have been clearer that the contemplation of the law is that a husband cannot rape his wife.

What then could be the legal reasoning underlying this position of the law? This will bring us back to the question: is the right to sexual intercourse with his wife which inures to a husband, and imposes a corresponding obligation/duty of conjugality on the wife, unfettered and/or absolute? Should there be circumstances under which a husband's exercise of his right to sexual intercourse with his wife could eventually amount to rape? Could this jurisprudential disposition be a reflection of the residual patriarchalism preponderant in African society? The expression of the partriachalistic chauvinism in customary law marriages in Africa can have no better expression than as expressed by Eja (2003: 88) below:

In traditional Africa, the position of the wife vis-à-vis her husband is one of absolute subservience. She must habitually obey her husband and must never be seen as raising her voice against him. Whatever protest she has, she must register the same at the 
appropriate quarters. She has to rear children to keep the man's lineage alive and has to work on the man's farm to support the family. In a polygamous home, sexual intercourse is at the man's option and at his absolute discretion. Sometimes, a woman may have to wait for months before it is her turn. She is a tool for labour and for commerce, and may never want to assert any right. Nevertheless, parties remain husband and wife.

Beginning with the last question in the last paragraph, the draftsmen of the matrimonial cause laws in Nigeria could be absolved of the allegation of partiachalism or male chauvinism as some scholars have tended to interpret the Nigerian matrimonial jurisprudence as being overly female-friendly. Such concepts as alimony, custody of children, maintenance, settlement of property, damages, use of husband's name, etc. have been adjudged by some as concepts meant for security and overall well-being of the female partner in, and outside marriage. $A$ fortiori, the concept of the incapacity of a woman (by extension wife) to rape a man (by extension husband) would come in handy for some to buttress the female-friendliness of the Nigerian matrimonial jurisprudence. Again, the Black's Law Dictionary clearly states that the exemption of a husband from raping his wife is of common law origin, it is not necessarily of African origin, or peculiar to Africa. Be that as it may, the rationale for the jurisprudential foreclosure of rape on a husband against his wife is yet to be unraveled.

We now return to the issue of whether the right to sexual intercourse which the husband enjoys is absolute. For those who think that it is absolute and unfettered (Onamade, 2008: 633), what justification do they have to hold such a view? The wordings of the marital rites seem to suggest that the commitments made at the point of exchange of vows are absolute. The catholic marriage rites, for instance, are as follows:

I, ------- take you, --------, to be my lawfully wedded husband/wife, to have and to hold, from this day forward, for better, for worse, for richer, for poorer, in sickness and in health, until death do us part.

The Islamic marital rites/vows have similar wordings and connotations. They are as follows:

Bride

I, --------, offer you myself in marriage in accordance with the instructions of the Holy Quar'an and the Holy Prophet, peace and blessing be upon him. I pledge, in honesty and with sincerity, to be for you, an obedient and faithful wife.

Groom

I, --------, pledge, in honesty and sincerity, to be for you, a faithful and helpful husband.

The rituals of these marital vows may suggest that the commitments made in sealing the union are absolute and unfettered, as long as the union subsists. The nature of the vows seems to confer a terminal consent to the husband to enjoy all the obligations/duties (including the obligation of conjugality) which the wife owes him. This may have informed the reasoning of the draftsmen of the matrimonial laws in Nigeria. They may have reasoned that since the fundamental ingredient in the crimen raptus is consent, the reasoning goes, the wife, having granted a terminal consent (as it were) to her husband the day she professed for better, and for worse, and until death do us part, she terminally absolved her husband from criminal imputation of rape allegation.

Is there anything in life that is absolute? Even legally speaking, is there any right that the carrier of the right enjoys absolutely? Since there cannot be any right in life that can be 
absolute, even the right to sexual intercourse which a husband enjoys in matrimony cannot be said to be absolute. If even the marriage itself that confers the marital rights and corresponding obligations is not absolute, as same can be dissolved given the existence of certain preconditions, then even the right to sexual intercourse which inures to a husband can be derogated from, depending, of course, on the existence of specific preconditions. Arguing in support of the fact that the right to sexual intercourse enjoyed by the husband in a marital union is not absolute, Eja (2003: 93) maintains as follows:

Spouses must respond to each other's reasonable sexual demands. It would be unreasonable, for instance, if a spouse is in poor health condition, or in a poor state of mind, and the other is pressing for sexual intercourse.

\section{SOCIO-CULTURAL AND PSYCHOLOGICAL EFFECTS OF RAPE ON THE RAPE- VICTIM}

Rape is an ontological aberration. This is so because sexual intercourse is a social activity, and because it is a social activity, it cannot (should not) be done alone is it should necessarily require another. One of the immediate implications of this is that since sexual intercourse needs another person of the opposite sex to perform, consent becomes a conditio sine qua non. It is because of the lack of consent in the rape-phenomenon that it is considered an ontological aberration.

Most cultures and societies have put in place various regimes of customs and taboos intended primarily for the protection of the sanctity and purity of the sexual intercourse activity. Rape, therefore, is a cultural and societal taboo in all Nigerian cultures (Makinde et al., 2016). In fact, because of the degree of the unimaginability of the desecration of the sanctity and purity of sexual intercourse by the act of rape, most Nigerian cultures have intensified its unacceptability by engaging in acts/behaviour that tends to stigmatise and disdain even the rape-victim.

Primarily, the rape-victim is psychologically traumatised by the forceful invasion of her vulva which leaves her with physical bruises (or injuries and cuts, depending on the size of the instrument of the invasion). The physiological destruction of the woman's genitals leaves her with a tremendous psychological impact that takes quality time and attention to overcome. Psychologically, the rape-victim gets to deal with mental pathologies such as insomnia, depression, aggression, fear, withdrawnness, etc. other consequences of rape on the rape-victim include unwanted pregnancy, diseases, malfunction of the woman's biological system, paranoia, self-pity, suicide tendencies, etc. The rape-victim's assailant inflicts a primary trauma on his victim, which primary consequences are variegated and multifaceted.

Unfortunately, the rape-victim, in most climes of the world, but most especially in many Nigerian cultures, is practically re-traumatised by the society in which she lives. The rape-victim is disdained by her peers, despised by her parents, deprived by her society, and demonised by her religious handlers. Very often, the rape-victim is accused of flirting, or making herself available to the assailant, or dressing provocatively like wearing boobsblasting blouses and sensational mini items that reveal voluptuous features and lust-inducing parts. Some Nigerian cultures use these (victim blaming) as alibis and contributory factors that activated the moral decadence of the rape-victim's assailant (Ogar \& Edor 2020). In cases where the assault ends up in court, defence lawyers/counsel ostensibly ridicule the rapevictim in the guise of advocacy prowess, thereby compounding the trauma of the rape-victim. Victim-blaming and other acts of societal pressure on the rape-victim are collectively known 
as secondary victimisation. The rapist, that is the rape-victim's assailant, has primarily victimised his victim in the first instance, then the society accentuates, escalates, complicates and compounds the trauma inflicted on the rape-victim by her primary assailant, thereby becoming the secondary assailant itself.

\section{CONCLUSION}

Rape, otherwise known as crimen raptus, is one of the social maladies the Nigerian society is confronting today. It has always been there, but the combination of other social factors like joblessness, drug abuse, institutional corruption, moral decadence, etc. have exacerbated the preponderance of the social phenomenon. It has been shown herein that in the Nigerian criminal jurisprudence, a woman is perceived as being physiologically incapable of rape, and a wife's nuptial consent is deemed as being coterminous with consent for the exercise of the conjugal right by her husband in perpetuity, therefore terminally foreclosing her husband from criminal imputations of raping his wife. So it would appear that once a woman is established to be the wife of an accused person standing rape trial, the court becomes automatically divested of jurisdiction for the continued entertainment of the matter. However, given the fact that medicare and scientific research have made it possible for a man who is otherwise psychologically ill-disposed for sexual intercourse to have an inducedgenital-erection, it is time the laws of rape were reviewed in Nigeria. Again, it has been argued herein that it would be a form of slavery to maintain the view that a wife's nuptial consent operates in perpetuity to confer the right, at all times, of exercise of conjugality on the husband, irrespective of the emotional and physical mood of the wife. Since no right on earth is absolute, a husband's right to sexual intercourse with his wife should not be absolute either. This way, a limited allowance could be given for a husband to be guilty of raping his wife.

It was exposed herein that apart from the primary trauma that the rape-victim undergoes, societal practices and behaviours avail themselves to complicate the pains and fangs inflicted upon the rape-victim by her primary assailant. These practices and behaviours are collectively referred to as secondary victimisation, and they operate to re-traumatise the rape-victim. The phenomenon of secondary victimisation is unnecessary, as there is no ontological/necessary connection between the act of rape and the monumental pressure the rape-victim is made to come under by society. Contemporary Nigerian societies must reconsider their various cultures and make them develop customs that will ameliorate and attenuate the hardship and trauma occasioned by the rape-victim's primary assailant, rather than fastening unto customary practices that exacerbate the rape-victim's travails, leaving her with the semblance of sexual objectification.

\section{REFERENCES}

Eja, E. E. (2003). A Manual of Family Law in Nigeria. Lagos: Amazingrafiks Ltd.

Felix, E. O., Chukwuma, U. J., Kenneth, E. C., \& Chudi, O. O. (2019). Prevalence of Sexual Assault in Abakaliki, Ebonyi State, Nigeria. Global Journal of Health Science, 11(11), 192. https://doi.org/10.5539/gjhs.v11n11p192

Garner, B. A., \& Black, H. C. (2007). Black's law dictionary: Deluxe edition. St. Paul, MN: West Group.

Makinde, O. A., Odimegwu, C. O., Abdulmalik, J. O., Babalola, S. O., \& Fawole, O. I. (2016). Gender-based violence following social media acquaintance in Nigeria. 
African Journal of Reproductive Health, 20(4), 67-76. https://doi.org/10.29063/ajrh2016/v20i4.7

Merab, Y. E. (2015). Changing Trends in Dreamboat Children's Theatre, Calabar, Nigeria. A Journal of Theatre \& Media Studies, 1(1),

Nyoroh, V. (2004). Legal Security to Christian Marriage. Calabar: Jamel Publishers.

Ogar, T. E., \& Edor, E. J. (2020). Creative Cultural Synergy: Towards the Africa of the Future. PINISI Discretion Review, 4(1), 135-150.

Ohayi, S. R., \& Ezugwu, E. C. (2019). Prevalence and pattern of genital injuries among adolescent rape victims attending Enugu State University Teaching Hospital, South East Nigeria. Journal of Obstetrics and Gynaecology, 39(2), 190-194. https://doi.org/10.1080/01443615.2018.1474189

Onamade, P. A. (2008). Cases and Materials on Criminal Law. Lagos: Philade Co. Ltd.

Opasina, O. K. (2016). The interplay between fragility and crime in African states: a case study of Nigeria and Côte d'Ivoire. International Social Science Journal, 66(221-222), 285-301. https://doi.org/10.1111/issj.12126

Smith, D. J. (2016). Modern Marriage, Masculinity, and Intimate Partner Violence in Nigeria. In Marital Rape (pp. 41-54). https://doi.org/10.1093/acprof:oso/9780190238360.003.0004

The Criminal Code Act. (2003). Cap. C38, Laws of the Federation of Nigeria.

The Penal Code Act (1963). Cap. 89, Laws of the Northern of Nigeria.

Yta, E. M. (2015). The Arts Teacher: Enriching Pedagocy through Arts Based Instruction. A Journal of Theatre \& Media Studies, 1(1), 111-117. 